\title{
The association between coronary artery disease and nonalcoholic fatty liver disease and noninvasive imaging methods
}

\author{
Mustafa Koplay ${ }^{1}$, Mustafa Gok ${ }^{2}$, Mesut Sivri ${ }^{1}$
}

\begin{abstract}
Coronary artery disease (CAD) is the number one cause of death globally and imaging plays a pivotal role in the diagnosis and management of CAD. With the improvements in technology, noninvasive imaging methods become more widely used in the management of CAD. Non-alcoholic fatty liver disease (NAFLD) is a clinicopathological syndrome which affects a substantial proportion of general population and is a component of the metabolic syndrome (MetS). Histopathologic analysis is the reference standard to detect and quantify fat in the liver, but results are vulnerable to sampling error. Imaging can be repeated regularly and allows assessment of the entire liver, thus avoiding sampling error so imaging is in key role in the management of NAFLD as in CAD. As NAFLD is a component of MetS, it is associated with increased risk for CAD. Recent studies suggest a more complex picture of the interrelation between NAFLD, MetS and CAD, and raised the possibility that NAFLD might not only be a marker but also an early mediator for CAD. So early detection of NAFLD and its management with noninvasive imaging methods can be very crucial in the control of CAD which is the number one cause of death globally.
\end{abstract}

Keywords: coronary artery disease, ultrasonography, nonalcoholic fatty liver disease, computerised tomography, magnetic resonance imaging

\section{INTRODUCTION}

\section{Coronary Artery Disease}

The World Health Organization (WHO) categorises Cardiovascular Diseases (CVDs) as a group of disorders of the heart and blood vessels. Coronary Artery Disease (CAD) is the most prevalent among those disorders. CVDs are the number one cause of death globally: with more people dying annually from CVDs than from any other cause. In 2012, CVD's accounted for $31 \%$ of all global deaths, with an estimated 17.5 million people dying from the disease. Of these deaths, an estimated 7.4 million were attributed to CAD and 6.7 million were due to stroke (1).

Imaging plays a pivotal role in the diagnosis and management of CAD and is used for the detection of underlying coronary artery stenosis in patients with stable or chronic chest pain, the assessment of myocardial scar and viability for assessing prognosis, or for predicting complications. Conventional coronary angiography still remains the standard of reference for the diagnosis of CAD. In 1999, more than 1.8 million conventional angiographic examinations were performed in United States alone (2). Conventional angiography offers the advantage of high spatial resolution and the option of direct performance of interventions such as balloon dilatation or coronary stent placement. However, only one third of all conventional coronary angiographic examinations in the United States are performed in conjunction with an interventional procedure. The rest are performed only for diagnostic purposes-namely, only for verification of the presence and degree of CAD (2). In light of limited health care resources and in the interest of patients who undergo unnecessary invasive tests, reliable noninvasive imaging tools for CAD is required for diagnostic and prognostic purposes. Summary of noninvasive cardiac imaging modalities, their prior and general imaging sides are provided in Table 1.

1 Selcuk University, Medical Faculty, Turkey

2 Department of Radiology, Medical Faculty of Adnan Menderes University, Turkey

Received: 14 Jan 2019, Accepted: 13 Jul 2019
Correspondence: Mustafa Koplay

Selcuk University, Medical Faculty, Turkey

E-mail:koplaymustafa@hotmail.com

(C) 2019 by the authors; licensee Modestum Ltd., UK. This article is an open access article distributed under the terms and conditions of the Creative Commons Attribution License (http://creativecommons.org/licenses/by/4.0/). 
Table 1: Summary of cardiac noninvasive imaging modalities and their imaging sides (prior imaging sides are mentioning in bold)

\begin{tabular}{ccc}
\hline & & Cardiac Imaging Types \\
\cline { 2 - 3 } Cardiac Imaging Modality & Coronary arteries & $\begin{array}{c}\text { Detection of ischemic and } \\
\text { infarcted myocardium }\end{array}$ \\
\hline CT & + (with coronary CTA) & - \\
\hline MR & $+($ with coronary MRA $)$ & + \\
\hline SPECT & - & - \\
\hline PET & - & - \\
\hline
\end{tabular}
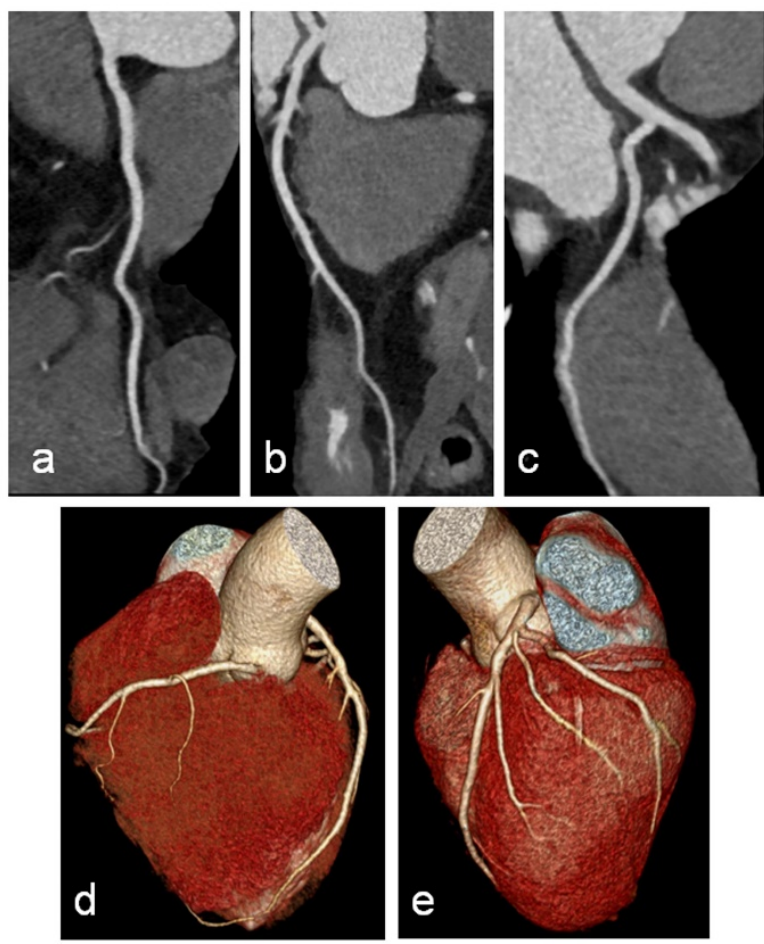

Figure 1: Images of excellent image quality using the prospective ECG-triggered coronary CTA in a patient 52 year-old male with atypical chest pain, an averaged heart rate of 68 beat/min. Curved reformations images show excellent image quality (a) the normal right coronary artery (RCA), (b) left anterior descending artery (LAD), (c) circumflex artery and $(d, e)$ $3 D$ volume rendering reformation images

\section{Noninvasive Imaging Methods for Coronary Artery Disease}

Also conventional coronary angiography still remains the standard of reference for the diagnosis of $C A D$, it also can be diagnosed noninvasively with cross-sectional imaging techniques. These techniques are Cardiac Computed Tomography Imaging (CT), Cardiac Magnetic Resonance Imaging (MRI), Positron Emission Tomography (PET) and 4Single Photon Emission Computed Tomography (SPECT).

\section{Cardiac CT}

Cardiac CT has multiple clinically relevant applications, including coronary artery calcium scoring, coronary computed tomography angiography (CTA), global and regional left ventricular function assessment, and most recently the assessment of myocardial CT perfusion (CTP) (3). Most of the cardiac CT exams performed today are coronary CTAs.

Due to the heart's continuous motion effect, imaging of the heart has always been technically challenging. CT imaging of the heart was facilitated by the introduction of electron-beam CT (4), multi-detector row CT "MDCT" (5) and recently dual source CT systems "DSCT" (6). These modalities allow for fast volume coverage and high spatial and temporal resolution. Previously, CT applications for the assessment of CAD were almost exclusively based on detection and quantification of coronary arterial calcium (7). However, the diagnostic value of $C T$ coronary calcium measurements and the exact role of this marker for cardiac risk stratification remain unclear and controversial (8). However, with the introduction of fast ECG-synchronized MDCT and DSCT image acquisition in the heart have enabled imaging of the coronary arterial tree with a combination of speed and spatial resolution that has been unparalleled by other noninvasive imaging modalities (Figure 1 and 2). High spatial resolution contrast medium enhanced CT angiography for noninvasive 


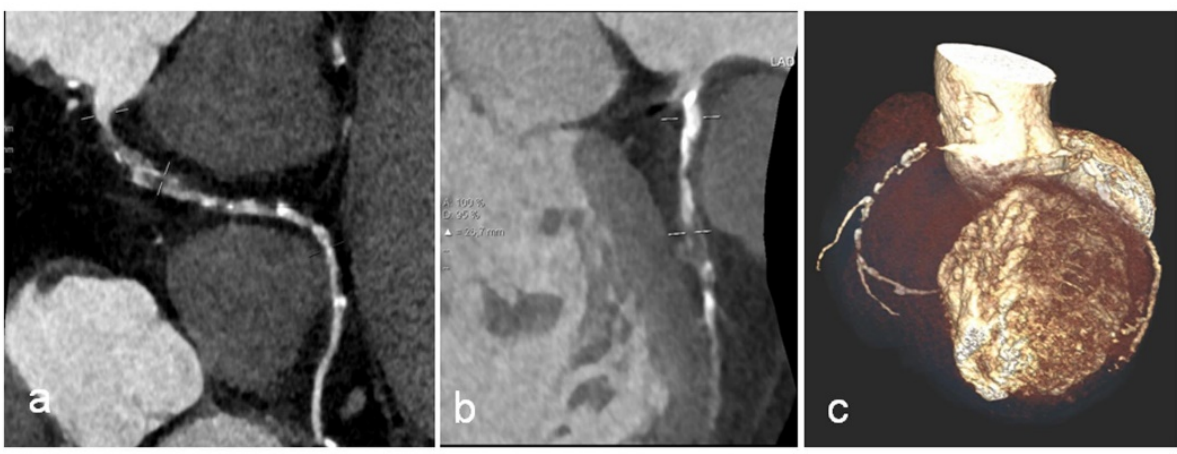

Figure 2: Images obtained using the retrospective ECG-triggered coronary CTA in a patient 56 year-old male with atypical chest pain, an averaged heart rate of 92 beat/min. In multiplanar reconstruction $(a, b)$ and $3 D$ volume rendered (c) images shows soft and calcified plaques which causes severe luminal stenosis and occlusion in the right coronary artery (a) and in left anterior descending artery $(b)$ in a patient with grade 3 hepatosteatos

interrogation of the coronary arterial tree is enabling detection and grading of coronary artery stenosis (9). An inherent advantage of CT for imaging of the coronary arteries is the cross-sectional nature of this technology, whereas conventional angiography displays only the vessel lumen and degree of luminal narrowing in cast like manner (10). Contrast enhanced CT delineate calcified and non-calcified lesions within the coronary artery wall that may or may not cause luminal stenosis (11).

A major limitation of coronary CTA is not knowing the physiological significance of the stenosis. Stress myocardial CTP is a novel examination that provides both anatomic and physiological information. It has been illustrated that combined CTA/CTP protocol improves diagnostic accuracy to detect hemodynamic significant stenosis when compared with CTA alone $(12,13)$; this combined protocol can also be accomplished at a radiation dose comparable to nuclear myocardial perfusion imaging exams (13).

\section{Cardiac MRI}

Diagnostic imaging has played an important role in the proper assessment and management of CAD. Developments in rapid MRI technology and its application to cardiac imaging have shown that MRI has great potential for the evaluation of CAD and cardiac diseases in general. During the past decade with improvements in gradient hardware technology, including the ability of MRI systems to manipulate and process raw data more rapidly have brought the vision of a complete cardiac examination that could be performed in a relatively short time. A single examination that provides information on 1- myocardial wall motion abnormalities, 2- infracted myocardial tissue, 3- regional perfusion reserve and 4- coronary arteries can be envisioned on the basis of MRI with tagging and dobutamine stress testing, late gadolinium enhanced (LGE) measurement of regional perfusion (cardiac MR perfusion) and advances in MR coronary angiography (coronary MRA), respectively (14).

According to 2010 Expert Consensus Document on Cardiovascular Magnetic Resonance (ACCF/ACR/AHA/NASCI/SCMR) the potential indications for the use of cardiovascular MRI is recommended as follow for CAD (15);

- Coronary MRA may be used for identifying coronary artery anomalies and aneurysms and for determining coronary artery patency. In specialized centres, coronary MRA may be uniquely useful in identifying patients with multivessel CAD without exposure to ionizing radiation or iodinated contrast medium.

- The combination of cardiac MR stress perfusion, function and LGE allows the use of MRI as a primer form of testing for; identifying patients with ischemic heart disease when there are resting ECG abnormalities or an inability to exercise, defining patients with large vessel $C A D$ and its distribution who are candidates or interventional procedures or determining patients who are appropriate candidates for interventional procedures.

- LGE-MRI may be used for identifying the extent and location of myocardial necrosis in individuals suspected of having or possesing chronic or acute ischemic heart disease.

\section{PET and SPECT}

Stress myocardial perfusion imaging (MPI) may help in the noninvasive assessment of CAD such that only patients likely to benefit from revascularization can be referred for invasive coronary angiography. Two mature nuclear imaging techniques are available for stress MPI; SPECT and PET (16). 
Technological advances have improved both techniques since their introduction. Electrocardiographic gating provides myocardial function data to be integrated with perfusion data, increasing the specificity of noninvasive assessment, and can be performed with both PET (17) and SPECT (18). Attenuation correction also improves specificity and although it has been used successfully with SPECT, attenuation correction is universally applied during PET image processing (19). Recent advances in data acquisition and processing may also lead to improve image quality and possibly diagnostic accuracy with both techniques.

PET MPI has several theoretical advantages compared with SPECT MPI. PET cameras do not require physical collimation, resulting in better detector efficiency (count sensitivity) and improved spatial resolution. The short half-life of PET radiotracers results in higher signal-to-noise ratios and consequently better image quality compared with SPECT (19). PET MPI may also have an advantage with respect to radiation exposure. In literature exposures of up to 22 millisieverts (mSv) for standard doses of TI-201 and 6.6 to $7.1 \mathrm{mSv}$ for single dose of Tc-99m were measures with the two most commonly used SPECT radiotracers (20).

Now we are going to highlight what is NAFLD and about its imaging techniques.

\section{Nonalcoholic Fatty Liver Disease (NAFLD)}

Fatty liver is a term used for a wide spectrum of conditions characterized histologically by triglyceride (TG) accumulation within the cytoplasm of hepatocytes. The prevalence of fatty liver in the general population is about $15 \%$, but it is higher among those who consume large quantities ( $>60 \mathrm{~g} /$ day) of alcohol $(45 \%)$, those with hyperlipidaemia $(50 \%)$ or obesity (body mass index "BMl" $\left.>30 \mathrm{~kg} / \mathrm{m}^{2}\right)(75 \%)$, and those with both obesity and high alcohol consumption (95\%) (20). The two most common conditions associated with fatty liver are alcoholic liver disease and nonalcoholic fatty liver disease (NAFLD). Alcoholic liver disease is caused by excess alcohol consumption, although the NAFLD is related to abdominal obesity, type 2 diabetes, insulin resistance, hypertension and dyslipidaemia (the typical components of the metabolic syndrome "MetS"). There is a strong association between NAFLD and diabetes risk. In addition, increasing epidemiological evidence suggests that there is a bidirectional relationship between NAFLD and type 2 diabetes and that NAFLD may precede and/or promote the development of type 2 diabetes. An individual's risk of developing diabetes is increased approximately 5 -fold if they have NAFLD. The association between NAFLD and type 2 diabetes could be explained by the insulin resistance, dyslipidaemia and hepatic triglyceride (TG) accumulation in NAFLD and defective Bcell in type 2 diabetes mellitus. NAFLD and type 2 diabetes share multiple cardiometabolic risk factors and pathophysiological (proinflammatory and profibrotic) pathways (21). Other relatively common conditions related with fat accumulation in the liver include viral hepatitis (hepatitis B and C) and the use or overuse of certain drugs (steroids, chemotherapeutic agents, amiodarone, valproic acid). Uncommon associated conditions include dietary and nutritional abnormalities (total parenteral nutrition, rapid weight loss, starvation, surgery) and congenital disorders (metabolic disorders, storage disorders, cystic fibrosis, dysmorphic syndromes associated with obesity) (22).

These conditions all cause a TG accumulation (steatosis) within hepatocytes by altering the hepatocellular lipid metabolism, in particular, by causing defects in free fatty acid metabolic pathways (23). In many conditions associated with fatty liver, steatosis may progress to steatohepatitis "in NAFLD we called this condition nonalcoholic steatohepatitis (NASH)" (with inflammation, cell injury, or fibrosis accompanying steatosis) and the cirrhosis (24). However, because progression to steatohepatitis is uncommon, a "two-hit" model has been proposed. The "first-hit" is the cytoplasmic deposition of TG in hepatocytes, which may take the hepatocytes more vulnerable to a "second-hit" but which, in the absence of the second-hit, doesn't lead to progressive disease. The second-hit has not yet been identified but is thought to represent a constellation of superimposed cellular events that promote inflammation and cell injury and incite progression to fibrosis and cirrhosis (23).

\section{Noninvasive Imaging Methods for Nonalcoholic Fatty Liver Disease}

The diagnostic reference standard for the assessment of fatty liver is liver biopsy and histologic analysis. It also can be diagnosed noninvasively with cross-sectional imaging techniques. These techniques are Ultrasonography (USG), Computerised Tomography (CT) and Magnetic Resonance Imaging (MRI).

\section{USG}

USG is the simplest imaging method for the detection of fatty liver. The examination usually is performed by using a low-frequency $(2-5 \mathrm{MHz})$ convex transducer; however, the choice of transducer depends on the patient's body habitus. The echogenicity of the normal liver equals or minimally exceeds that of the renal cortex or spleen. Intrahepatic vessels 

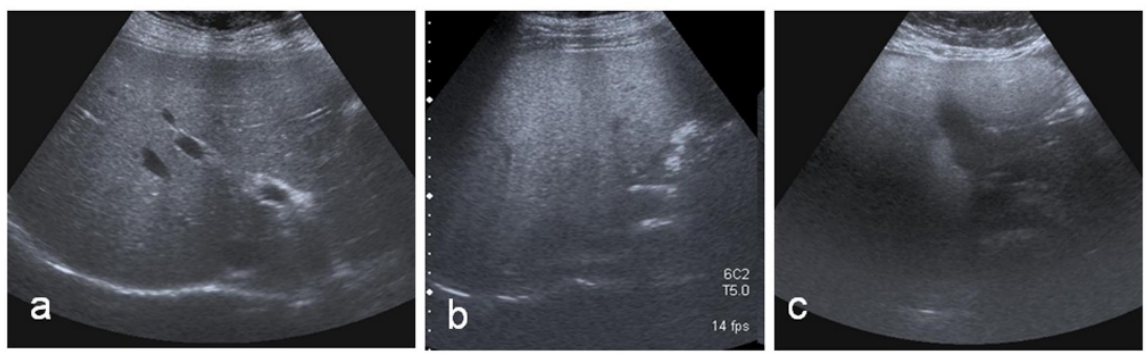

Figure 3: Ultrasonographic images show the hepatosteatos grades. a) grade 1: mild fatty liver, b) grade 2: moderate fatty liver, c) grade 3: severe fatty liver

and diaphragm are sharply demarcated, and posterior aspects of the liver are well depicted. Fatty liver results in increased echogenicity (brightness) of the liver parenchyma in comparison with renal cortex and spleen. This occurs because of the increasing interfaces created in the liver by lipid accumulation, leading to more echoes returning to the transducer, thus making the liver appear bright (25).

The quality of the USG examination is highly operator dependent, and the diagnosis and characterization of fatty liver disease at USG are based mainly on a subjective assessment of liver echogenicity (Figure 3). Several methods have been proposed for the quantitative grading of fatty liver at USG as follow: mild, characterized by mildly increased liver echogenicity and clear depiction of hepatic and portal vein walls; moderate, with increased liver echogenicity obscuring the hepatic and portal vein walls; severe, with increased liver echogenicity and significant posterior shadowing that impairs evaluation of the deep liver parenchyma and diaphragm $(25,26)$.

The hepatorenal sonographic index (HRI) is a sensitive noninvasive method for steatosis quantification. It can quantify the steatosis that is more reliable than subjective assessment alone. This technique with software support compares the brightness of the liver parenchyma with brightness of renal parenchyma, and after their division, you got a HRI coefficient. In a normal liver, HRI is in the range from 1.00 to 1.04. Liver steatosis was classified according to HRI values as mild (HRI $=1.05-1.24)$, moderate $(H R I=1.25-1.64)$ or severe $(H R I \geq 1.65)(18,19)$. It can diagnose small amounts of liver fat that would be missed by conventional sonography. It is reproducible and operator independent and can serve as an efficient tool to follow patients with steatosis (27).

USG based qualitative assessment of steatosis has been reported to lack of intraobserver reproducibility and interobserver reliability (25). An altered renal parenchymal renal parenchymal echotexture associated with renal parenchymal disorders may affect USG evaluations of the liver. Moreover, the presence of hepatic fibrosis in some patients makes the linear correlation between fatty infiltration and liver echogenicity unreliable (28).

\section{CT}

Unenhanced CT is considered the best CT method for estimation of liver fat, because it involves simple measurement of liver attenuation in Hounsfield units (HU). The measurement of attenuation at unenhanced $\mathrm{CT}$ is based on the physical characteristic of $\mathrm{X}$-ray penetration from the tissue. Hepatic attenuation values are inversely correlated with the amount of liver fat; therefore, they decrease proportionately with increasing liver fat content (29). Contrast-enhanced CT, on the other hand, is not the most reliable method for detecting the hepatic fat content, because the attenuation characteristics depend on various factors related to the contrast material. Contrast medium-related factors such as iodine concentration, colume and rate of injection, and scanning delays influence the hepatic attenuation to varying degrees and may mask subtle differences in attenuation caused by changes in fat content. Qualitative assessment of hepatic attenuation performed at contrast-enhanced $\mathrm{CT}$ by using splenic attenuation as a control may produce misleading results because the spleen enhances to a greater degree than the liver, even with the commonly used portal venous phase examinations (30).

For qualitative estimation of liver fat in $\mathrm{CT}$, comparing the attenuation of liver with that of spleen is performed. The spleen serves as a good internal control for comparison with the liver because splenic attenuation is unaffected by various diffuse pathologic processes and because the spleen is located in the same cross section as the liver (31). At unenhanced $\mathrm{CT}$, a normal liver has higher attenuation than a normal spleen. When the liver has lower attenuation than the spleen at unenhanced $\mathrm{CT}$, a diagnosis of hepatic steatosis may be considered (Figure 4). For qualitative grading following subjective five-point grading system has been proposed for describing the degree of hepatic steatosis on the basis of hepatic attenuation and visualization of the hepatic vessels (hepatic and portal veins): in grade 1, hepatic vessels show lower attenuation than hepatic parenchyma out to the peripheral third of liver; in grade 2 , hepatic vessels show lower attenuation than hepatic parenchyma out to the middle third of liver; in grade 3 , hepatic vessels show lower 


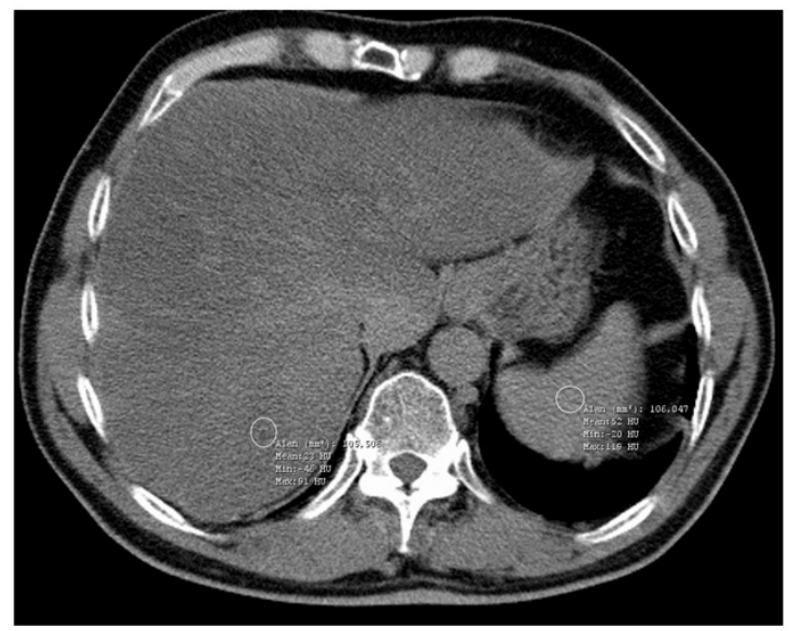

Figure 4: CT evaluation of fatty liver using a liver-to spleen attenuation difference with unenhanced CT. Axial image shows diffuse fatty infiltration of liver with attenuation much lower than the spleen on visual analysis .Regions-of-interest (white circles-ROI) shows mean hepatic attenuation (23 HU) and splenic attenuation (52 HU) with -29 HU a liver-to spleen attenuation difference, pointing moderate-to-severe hepatosteatosis

attenuation than hepatic parenchyma in the central third of liver; in grade 4 , hepatic vessels show the same attenuation as that of hepatic parenchyma; in grade 5 , hepatic vessels show higher attenuation than that of hepatic parenchyma. Grade 5 has been associated with a CT finding of 30\% of greater macrovesicular steatosis (32).

For quantitative estimation of liver fat in $\mathrm{CT}$, available methods are hepatic attenuation measurement, calculation of the hepatic attenuation index and measurement of the hepatic attenuation difference at dual-energy CT. Hepatic attenuation measurement; In unenhanced $\mathrm{CT}$, the attenuation values measured in the normal liver is ranging from 50 to $65 \mathrm{HU}$ and typically higher than those measured in the spleen. This is because of presence of glycogen in the liver. Fatty infiltration is diagnosed when the hepatic attenuation is less than $48 \mathrm{HU}$. When calculating liver attenuation, more accurate values can be obtained by making the region of interest (ROI) as larger as possible (at least $1 \mathrm{~cm}^{2}$ ) and avoiding the inclusion of any large vessels or biliary structures (33). Calculation of the hepatic attenuation index; The hepatic attenuation index, which is an objective measure of fatty liver disease, is commonly obtained by calculating the ratio of hepatic attenuation to splenic attenuation (33). Measurement of the hepatic attenuation difference at dual-energy $C T$; Dual-energy $\mathrm{CT}$, which involves scanning with two different tube potentials (typically, 140 and $80 \mathrm{kVp}$ ), may be used to evaluate focal and diffuse fatty liver by measuring change in hepatic attenuation between images acquired at the lower and higher energy levels. The attenuation of fatty liver changes more markedly with the change in tube potential than does that of normal liver. An increase in fatty content leads to a decrease in $\mathrm{HU}$ at low energy; as the energy level increases, the fat attenuation increases (34). Raptopoulos et al. (34) found that an attenuation change by more than $10 \mathrm{HU}$ with a tube potential change from 140 and $80 \mathrm{kVp}$ was indicative of fatty infiltration of more than $25 \%$.

MRI

Chemical shift gradient-echo (GRE) imaging with in-phase and out-of-phase acquisitions is the most commonly used MRI technique for evaluation of fatty liver. The signal intensity (SI) of the normal liver parenchyma is similar on in-phase and out-of-phase images. Fatty liver may be present if there is a SI loss on out-of-phase images in comparison with inphase images, and the amount of hepatic fat present can be quantified by assessing the degree of SI loss (35). Fat deposition also can be diagnosed by observing the SI loss of liver on MR images after the application of chemical fat saturation sequences, but this method is less sensitive than is chemical shift GRE imaging for the detection of fatty liver (22).

MR spectroscopy (MRS) is one of the most accurate methods for noninvasive assessment of fatty liver. Localized or single-voxel MRS provides information about chemical composition in a normal organ and chemical changes in the progression of disease. The values obtained with MRS show good correlation with the results of liver biopsy, and has been promoted as an optimal method for estimating the hepatic TG content (36). The advantages offered by MRS for fat quantification are its ability to determine the absolute liver fat concentration and its high sensitivity for detecting small amounts of hepatic TG and subtle changes in hepatic TG content during treatment. The disadvantages of MRS are being complex of analysing methods and because of the variability in results. The results also may vary because of 
Table 2: Reported sensitivities and specificities for each noninvasive imaging methods for detection of fatty liver deposition $(24,28,37)$

\begin{tabular}{ccc}
\hline Noninvasive Imaging Method & Sensitivity & Specificity \\
\hline USG & $60 \%-100 \%$ & $77 \%-95 \%$ \\
\hline CT (unenhanced) & $43 \%-95 \%$ & $90 \%$ \\
\hline MRI (chemical shift GRE) & $81 \%$ & $100 \%$ \\
\hline
\end{tabular}

Table 3: Possible pathophysiological bases for an association between NAFLD and accelerated atherosclerosis $(32,33,34)$

\begin{tabular}{|c|c|c|}
\hline Factors & Atherosclerosis & NAFLD \\
\hline \multicolumn{3}{|l|}{ Genetic predispositions } \\
\hline Atherogenic hyperlipidaemia & Associated with high LDL, VLDL and low HDL & $\begin{array}{l}\text { Prevalence of NAFLD most elevated in mixed hyperlipidaemia } \\
\text { with increased ALT }\end{array}$ \\
\hline Arterial hypertension & $\begin{array}{l}\text { Associated and partially reversible with a decrease } \\
\text { in hypertension }\end{array}$ & Patients with hypertension have a higher prevalence of NAFLD \\
\hline Hyperhomocysteinaemia & Associated & $\begin{array}{l}\text { Evidence from animal and human studies, including Hepatitis } C \\
\text { virus steatosis }\end{array}$ \\
\hline Type2 Diabetes mellitus (DM) & Strongly associated & $\begin{array}{l}\text { Very common in T2DM and a risk factor for the development } \\
\text { and progression of NAFLD }\end{array}$ \\
\hline Abdominal obesity & Strongly associated & $\begin{array}{l}\text { Associated with abdominal obesity and predictor of liver } \\
\text { fibrosis }\end{array}$ \\
\hline Systemic inflammation & $\begin{array}{l}\text { Associated with CRP and other acute-phase } \\
\text { proteins }\end{array}$ & Major determinant for the development of NAFLD \\
\hline MetS and Insulin resistance & Strongly associated & $\begin{array}{l}\text { Very common in MetS and a risk factor for the development } \\
\text { and progression of NAFLD }\end{array}$ \\
\hline Male gender & $\begin{array}{l}\text { Men }<60 \text { are twice as likely to be affected } \\
\text { compared with women }\end{array}$ & Female gender protected \\
\hline \multicolumn{3}{|l|}{ Environmental } \\
\hline High fat diet & Strong association with lifestyle & Reported in NAFLD and impared postprandial lipid metabolism \\
\hline Cigarette smoking & Strongly associated and reversible by quiting & Preliminary evidence \\
\hline Low antioxidants & Findings not conclusive & Findings nor conclusive \\
\hline Sedentariness & Independent association & $\begin{array}{l}\text { Associated with NAFLD; exercise is recommended as a } \\
\text { treatment }\end{array}$ \\
\hline
\end{tabular}

differences in MR systems and acquisition parameters and because fat quantification is performed in a small volume of liver tissue (37).

Review table for reported sensitivities and specificities for each noninvasive imaging modality for detection of fatty liver deposition (Table 2).

\section{The Association between CAD and NAFLD}

The importance of NAFLD and its relation with the MetS is increasingly recognized, and this has stimulated an interest in the possible role of NAFLD in the development of CAD (Table 3). In addition, we provided illustrative material possible mechanism of association between CAD and NAFLD (Figure 5). Indeed, the possible impact of NAFLD on CAD risk deserves particular attention in view of the implications for screening/surveillance strategies in the growing number of patients with NAFLD. Given the strong correlation between NAFLD and MetS risk factors (abdominal obesity, type 2 diabetes, insulin resistance, hypertension and dyslipidaemia), patients with NAFLD would be expected to have an increased risk of CAD. It is also possible to speculate that NAFLD itself might confer an excess of CAD risk over and above what would be expected due to the increased prevalence of the underlying MetS risk factors (42).

In recent studies, markers of subclinical atherosclerosis such as increased carotid artery intima-media thickness (IMT) and circulatory endothelial dysfunction, are demonstrated in NAFLD patients $(43,44)$. As in another study, it was hypothesized that fatty liver is a risk factor of early onset of atherosclerosis and that atherosclerosis begins in childhood and progresses through adulthood to form the lesions that cause symptomatic CAD. In one study, autopsy findings from 817 children (aged 2-19 years) who died of external causes (accident, homicide, suicide), were analysed (45). Atherosclerosis was two-fold more frequent in children with fatty liver then in those without fatty liver. It is noted that fatty liver might not only be marker but also an early indicator of atherosclerosis (46). It is also reported that the prevalence of NAFLD was significantly higher in patients with CAD compared with that found in the general population. Increased arterial stiffness is an established cardiovascular risk marker in several clinical settings and had been proposed to reflect the cumulative burden of cardiovascular risk factors on the vascular wall. Recent studies have reported strong associations between increased aortic stiffness and NAFLD, particularly at its more advanced stages (47). 


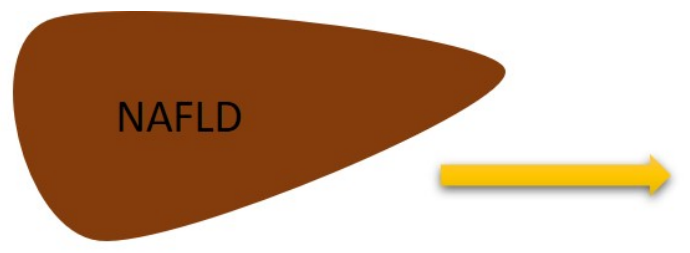

Oxidative stress

Atherogenic hyperlipidemia

Systemic inflammation

Inflammatory cytokines

MetS and Insulin resistance

Hyperhomocysteinaemia

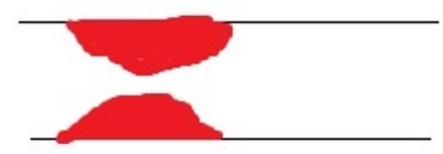

Coronary artery disease

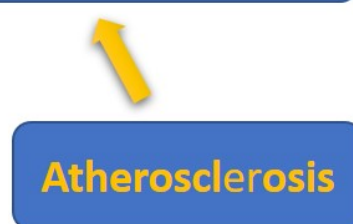

Figure 5: Image shows illustrative material possible mechanism of association between CAD and NAFLD

As a result, growing number of recent studies suggested that, NAFLD is associated with higher overall mortality and increased risk of future CVD events independent of classical risk factors and other prognostic factors. All these findings raise the possibility that NAFLD and atherosclerosis share common molecular mediators, and that NAFLD is not merely a marker but also an early mediator for atherosclerosis. So, it is important to evaluate the global CVD risk among patients diagnosed with NAFLD. These patients should be aggressively treated not only for their liver disease but also for underlying CVD risk factors, because many patients with NAFLD will have major CVD events and death prior to the development of liver disease.

\section{CONCLUSION}

Because CAD is the number cause of death globally, understanding CAD and preventing CAD are the main issue of global health system. The growing body of evidence suggesting that NAFLD and atherosclerosis share common molecular mediators and NAFLD is early mediator for atherosclerosis. Noninvasive imaging techniques are very important in management of these clinical conditions. Noninvasive imaging techniques are one of the key elements in the fight against CAD.

\section{REFERENCES}

1. World Health Organization (WHO) international media center fact sheet no:317, updated january 2015.

2. American Heart Association. 2002 heart and stroke stastical update. Dallas, TX; American Heart Association, 2001.

3. Cury RC, Nieman K, Shapiro MD, Butler J, Nomura CH, Ferencik M, et al. Comprehensive assessment of myocardial perfusion defects, regional wall motion, and left ventricular function by using 64-section multidetector CT. Radiology 2008;248:466-75. https://doi.org/10.1148/radiol.2482071478 PMid:18641250 PMCid:PMC2797649

4. Lipton $M$, Higgins $C B$, Boyd DP. Computed tomography of the heart; evaluation of anatomy and function. J Am Coll Cardiol 1985;5(Suppl 1):55-69. https://doi.org/10.1016/S0735-1097(85)80145-5

5. Dewey M, Zimmermann E, Deissenrieder F, Laule M, Dübel HP, Schlattmann P, et al. "Noninvasive coronary anjiography by 320-row computed tomography with lower radiation exposure and maintained diagnostic accuracy: comparison of results with cardiac catheterization in a head-to-head pilot investigation." Circulation 2009;120:867-75. https://doi.org/10.1161/CIRCULATIONAHA.109.859280 PMid:19704093

6. Achenbach S, Marwan M, Ropers D, Schepis T, Pflederer T, Anders K, et al. "Coronary computed tomography angiography with a consistent dose below $1 \mathrm{mSv}$ using prospective electrocardiogram triggered high-pitch spiral acquisition. Eur Heart J 2010;31:340-6. https://doi.org/10.1093/eurheartj/ehp470 PMid:19897497 
7. Agatston AS, Janowitz WR, Hildner FJ, Zusmer NR, Viamonte M Jr, Detrano R. Quantification of coronary artery calcium using ultrafast computed tomography. J Am Coll Cardiol 1990;15:827-32. https://doi.org/10.1016/07351097(90)90282-T

8. O'Malley PG, Taylor AJ, Gibbons RV, Feurstein IM, Jones DL, Vernalis M, et al. Rationale and design of Prospective Army Coronary Calcium (PACC) study: utility of electron beam computed tomography as a screening test for risk factor modification among young, asymptomatic, active-duty United States Army personel. Am Heart J 1999;137:932-41. https://doi.org/10.1016/S0002-8703(99)70419-9

9. Nieman K, Oudkerk $M$, Rensing BJ, van Ooijen $P$, Munne A, van Geuns RJ, et al. Coronary angiography with multi-slice computed tomography. Lancet 2001;357(9256):599-603. https://doi.org/10.1016/S01406736(00)04058-7

10. Topol EJ, Nissen SE. Our preoccupation with coronary luminology: the dissociation between clinical and angiographic findings in ischemic heart disease. Circulation 1995;92:2333-42. https://doi.org/10.1161/01.CIR.92.8.2333 PMid:7554219

11. Becker CR, Nikolaou K, Muders M, Babaryka G, Crispin A, Schoepf UJ, et al. Ex vivo coronary atherosclerotic plaque characterization with multi-detector-row CT. Eur Radiol 2003;13:2094-8. https://doi.org/10.1007/s00330003-1889-5 PMid:12692681

12. Rocha-Filho JA, Blankstein R, Shturman LD, Bezerra HG, Okada DR, Rogers IS, et al. Incremental value of adenosine-induced stres myocardial perfusion imaging with dual-source CT at cardiac CT angiography. Radiology 2010;254:410-9. https://doi.org/10.1148/radiol.09091014 PMid:20093513 PMCid:PMC2809927

13. Techasith T, Cury RC. Stress myocardial CT perfusion. An update and future perspective. J Am Coll Cardiol Img 2011;4:905-16. https://doi.org/10.1016/j.jcmg.2011.04.017 PMid:21835384

14. Reeder SB, Du YP, Lima JAC, Bluemke DA. Advanced cardiac MR imaging of ischemic heart disease. RadioGraphics 2001;21:1047-74. https://doi.org/10.1148/radiographics.21.4.g01jl281047 PMid:11452080

15. Hundley GW, Bluemke DA, Finn JP, Flamm SD, Fogel MA, Friedrich MG, et al. ACCF/ACR/AHA/NASCI/SCMR 2010 expert consensus document on cardiovascular magnetic rosenance. JACC 2010;55:2614-62. https://doi.org/10.1016/j.jacc.2009.11.011 PMid:20513610 PMCid:PMC3042771

16. Parker MW, Iskandar A, Limone B, Perugini A, Kim H, Jones $C$, et al. Diagnostic accuracy of cardiac positron emission tomography versus single photon emission computed tomography for coronary artery disease: a bivarite meta-analysis. Circ Cardiovasc Imaging 2012;5:700-7. https://doi.org/10.1161/CIRCIMAGING.112.978270 PMid:23051888

17. Dilsizian V, Bacharach SL, Beanlands R, Bergmann SR, Delbeke D, Gropler RJ, et al. ASNC imaging guidelines for nuclear cardiology procedures: PET myocardial perfusion and metabolism clinical imaging. J Nucl Cardiol 2009;16:651-81. https://doi.org/10.1007/s12350-009-9094-9

18. Holly TA, Abbott BG, Al-Mallah M, Calnon DA, Cohen MC, DiFilippo FP, et al. American Society of Nuclear Cardiology imaging guidelines for nuclear cardiology procedures. Single photon-emission computed tomography. J Nucl Cardiol 2010;17:941-73. https://doi.org/10.1007/s12350-010-9246-y PMid:20552312

19. Beanlands RS, Youssef G. Diagnosis and prognosis of coronary artery disease: PET is superior to SPECT: Pro. J Nucl Cardiol 2010;17:683-95. https://doi.org/10.1007/s12350-010-9253-z PMid:20589487

20. Shen L, Fan JG, Shao Y, Zeng MD, Wang JR, Luo GH, et al. Prevalence of non-alcoholic fatty liver among administrative officers in Shanghai: an epidemiological survey. World J Gastroenterol 2003;9:1106-10. https://doi.org/10.3748/wjg.v9.i5.1106 PMid:12717867 PMCid:PMC4611383

21. Hazlehurst JM, Woods C, Marjot T, Cobbold JF, Tomlinson JW. Non-alcoholic fatty liver disease and diabetes. $\begin{array}{lll}\text { Metabolism. 2016;65:1096-108. } \quad \text { https://doi.org/10.1016/j.metabol.2016.01.001 PMid:26856933 } & \text { 263. }\end{array}$ PMCid:PMC4943559

22. Hamer OW, Aguirre DA, Casola G, Lavine JE, Woenckhaus M, Sirlin CB. Fatty liver: Imaging patterns and pitfalls. RadioGraphics 2006;26:1637-53. https://doi.org/10.1148/rg.266065004 PMid:17102041

23. Angulo P. Nonalcoholic fatty liver disease. N Engl J Med 2002;346:1221-31. https://doi.org/10.1056/NEJMra011775 PMid:11961152

24. Lefkowitch JH. Morphology of alcoholic liver disease. Clin Liver Dis 2005;9:37-53. https://doi.org/10.1016/j.cld.2004.11.001 PMid:15763228 
25. Saadeh S, Younossi ZM, Remer EM, Gramlich T, Ong JP, Hurley M, Muller KD, Cooper JN, Sheridan MJ. The utility of radiological imaging in nonalcoholic fatty liver disease. Gastroenterology 2002;123(3):745-50. https://doi.org/10.1053/gast.2002.35354 PMid:12198701

26. Osawa $H$, Mory $Y$. Sonographic diagnosis of fatty liver using a histogram technique that compares liver and renal cortical echo amplitudes. J Clic Ultrasound 1996;24(1):25-9. https://doi.org/10.1002/(SICI)10970096(199601)24:1<25::AID-JCU4 > 3.0.CO;2-N

27. Webb M, Yeshua H, Zelber-Sagi S, Santo E, Brazowski E, Halpern Z, Oren R. Diagnostic value of a computerized hepatorenal index for sonographic quantification of liver steatosis. AJR Am J Roentgenol. 2009;192(4):909-14. https://doi.org/10.2214/AJR.07.4016 PMid:19304694

28. Mathiesen UL, Franzen LE, Aselius $H$, Resjö M, Jacabsson L, Foberg $U$, et al. Increased liver echogenicity at ultrasound examination reflects degree of steatosis but not of fibrosis in asymptomatic patients with mild/moderate abnormalities of liver transaminases. Dig Liver Dis 2002;34:516-22. https://doi.org/10.1016/S1590-8658(02)80111-6

29. Yajima $Y$, Narui T, Ishii M, Abe R, Ohtsuki M, Goto Y, et al. Computed tomography in the diagnosis of fatty liver: total lipid content and computed tomography number. Tohoku J Exp Med 1982;136:337-42. https://doi.org/10.1620/tjem.136.337 PMid:7071850

30. Panicek DM, Giess CS, Schwartz LH. Qualitative assessment of liver for fatty infiltration on contrast-enhanced CT: is muscle a better standart of reference than spleen? J Comput Assist Tomogr 1997;21:699-705. https://doi.org/10.1097/00004728-199709000-00004 PMid:9294555

31. Bydder GM, Chapman RW, Harry D, Bassan L, Sherlock S, Kreel L. Computed tomography attenuation values in fatty liver. J Comput Tomog 1981;5(1):33-5. https://doi.org/10.1016/0149-936X(81)90054-0

32. Lee SW, Park SH, Kim KW, Choi EK, Shin YM, Kim PN, et al. Unenhanced CT for assessment of macrovesicular hepatic steatosis in living liver donors: comparison of visual grading with liver attenuation index. Radiology 2007;244:479-85. https://doi.org/10.1148/radiol.2442061177 PMid:17641368

33. Park SH, Kim PN, Kim KW, Lee SW, Yoon SE, Park SW, et al. Macrovesicular hepatic steatosis in liver donors: use of CT for quantitative and qualitative assessment. Radiology 2006;239:105-12. https://doi.org/10.1148/radiol.2391050361 PMid:16484355

34. Raptopoulos V, Karellas A, Bernstein J, Reale FR, Constantinou C, Zawacki JK. Value of dual-energy CT in differentiating focal fatty infiltration of the liver from low-density masses. AJR Am J Roentgenol 1991;157:721-5. https://doi.org/10.2214/ajr.157.4.1892025 PMid:1892025

35. Venkataraman S, Braga L, Semelka RC. Imaging the fatty liver. Magn Reson Imaging Clin N Am 2002;10:93-103. https://doi.org/10.1016/S1064-9689(03)00051-5

36. Szczepaniak LS, Nurenberg P, Leonard D, Browning JD, Reingold JS, Grundy $S$, et al. Magnetic resonance spectroscopy to measure hepatic triglyceride content: prevalence of hepatic steatosis in the general population. Am J Physiol Endocrinol Metab 2005;288:E462-8. https://doi.org/10.1152/ajpendo.00064.2004 PMid:15339742

37. Ma X, Holalkere NS, Kambadakore A, Kenudson MM, Hahn PF, Sahani DV. Imaging-based quantification of hepatic fat: methods and clinical applications. RadioGraphics 2009;29:1253-80. https://doi.org/10.1148/rg.295085186 PMid:19755595

38. Choji T. Evaluation of fatty liver changes and fatty degeneration in liver tumors by $1 \mathrm{H}-\mathrm{MRS}$. Nippon Igaku Hoghasen Gokkai Zasshi 1993;53:1408-14.

39. Loria P, Lonardo A, Targher G. Is liver fat detrimental to vessels?: intersections in the pathogenesis of NAFLD and atherosclerosis. Clincal Science 2008;115:1-12. https://doi.org/10.1042/CS20070311 PMid:19016656

40. Grundy SM, Brewer Jr. HB, Cleeman JI, Smith Jr. SC, Lenfant C. Definition of metabolic syndrome: Report of the National Heart, Lung and Blood Institute/American Heart Association conference on scientific issues related to definition. Circulation 2004;109:433-8. https://doi.org/10.1161/01.CIR.0000111245.75752.C6

41. Cave M, Deaciuc I, Mendez C, Song Z, Joshi-Barve S, Barve $S$, et al. Nonalcoholic fatty liver disease: predisposing factors and the role of nutrition. J Nutr Biochem 2007;18:184-95. https://doi.org/10.1016/j.jnutbio.2006.12.006 PMid:17296492

42. Targher G, Arcaro G. Non-alcoholic fatty liver disease and increased risk of cardiovascular disease. Atherosclerosis 2007;191:235-40. https://doi.org/10.1016/j.atherosclerosis.2006.08.021 PMid:16970951 
43. Targher G, Bertolini L, Padovani R, Rodella S, Zoppini G, Zenari L, et al. Relations between carotid artery wall thickness and liver histology insubjects with nonalcoholic fatty liver disease. Diabetes Care 2006;29:1325-30. https://doi.org/10.2337/dc06-0135 PMid:16732016

44. Villanova N, Moscatiello S, Ramili S, Bugianesi E, Magalotti D, Vanni E, et al. Endothelial dysfunction and cardiovascular risk profile in nonalcoholic fatty liver disease. Hepatology 2005;42(2):473-8. https://doi.org/10.1002/hep.20781 PMid:15981216

45. Schwimmer JB, Deutsch R, Behling C, Lavine JE. Fatty liver as a determinant of atherosclerosis. Hepatology. 2005;42(Suppl):610A. https://doi.org/10.1002/hep.20842 PMid:16116629

46. Pacifico L, Nobili V, Anania C, Verdecchia P, Chiesa C. Pediatric nonalcoholic fatty liver disease, metabolic syndrome and cardiovascular risk. World J Gastroenterol 2011 14;17:3082-91. https://doi.org/10.3748/wjg.v17.i25.3012 PMid:21799647 PMCid:PMC3132252

47. Athyros VG, Tziomalos K, Katsiki N, Doumas M, Karagiannis A, Mikhailidis DP. Cardiovascular risk across the histological spectrum and the clinical manifestations of non-alcoholic fatty liver disease: An update. World J. Gastroenterol. 2015;21:6820-34. https://doi.org/10.3748/wjg.v21.i22.6820 PMid:26078558 PMCid:PMC4462722

$\diamond \diamond \diamond \diamond \diamond \diamond \diamond$

http://www.ejgm.co.uk 